\title{
Evaluation of Intrahepatic Bile Duct Variations in Magnetic Resonance Cholangiopancreatography
}

\author{
Paudel S, Joshi BR, Chand RC
}

Department of Radiology, TU Teaching Hospital, Maharajgunj, Kathmandu, Nepal

Received: March 20, 2020

Accepted: April 30, 2020

Published: June 30, 2020

Cite this paper:

Paudel S, Joshi BR, Chand RC. Evaluation of Intrahepatic Bile Duct Variations in Magnetic Resonance Cholangiopancreatography. Nepalese Journal of Radiology 2020;10(15):27-33. http://dx.doi.org/10.3126/njr. v10i1.28949

\begin{abstract}
Introduction: A detailed knowledge of normal branching pattern of intrahepatic bile duct and their variations is of utmost importance for any liver or biliary tract surgery to avoid severe post-surgery complications and morbidity. The objective of this study was to evaluate variations of intrahepatic bile ducts in Magnetic Resonance Cholangiopancreatography (MRCP) examinations in Nepalese population.
\end{abstract}

Methods: This quantitative, cross sectional study was performed in patients referred for MRCP examinations for various clinical indications to Tribhuvan University Teaching Hospital, Maharajgunj, Nepal. Data were collected for a period of four months from August to November 2019 after IRB approval. Convenience sampling was employed and a total of 90 examinations were included. Data were obtained from the 1.5T Magnetom Amira Siemens MRI scanner. The 3D MRCP images were visually analyzed and classified into 7 Types according to the classification given by Choi et al.

Results: In our study $47.8 \%$ patients had Type 1/normal IHBD ( $n=43) .20 \%$ had Type $2(n=18)$, $3.3 \%$ had Type $3 \mathrm{~A}(\mathrm{n}=3), 5.6 \%$ had Type 3B. Type $5 \mathrm{~A}(\mathrm{n}=5), 7.8 \%$ had $5 \mathrm{~B}(\mathrm{n}=7), 3.3 \%$ had Type $6(\mathrm{n}=3)$ and $6.7 \%$ had Type $7(\mathrm{n}=6)$. No patients were found to have Type 3C and Type 4 IHBD variation. Among the total number of Type 1 cases, $67.44 \%(n=29)$ were female and rest were male.

Conclusions: Typical IHBD was only found in a $47.8 \%$ patients and common other variations were also noted in our population. Type 2 and Type $5 \mathrm{~B}$ were found in $20 \%$ and $7.8 \%$ patients respectively.

Keywords: Common Bile Duct, Cystic duct, Intra Hepatic Bile Duct, Magnetic Resonance Cholangiopancreatography, Variation

Correspondence to: Dr. Birendra Raj Joshi

Department of Radiology

TU Teaching Hospital, Maharajgunj

Kathmandu, Nepal

Email: swasulav@gmail.com

\section{INTRODUCTION}

Normal biliary anatomy is seen in only $58 \%$ of the population. ${ }^{1}$ Magnetic resonance cholangiopancreatography (MRCP) is an excellent non-invasive imaging technique 
for visualization of detailed biliary anatomy. An accurate knowledge of normal branching pattern of intrahepatic bile duct and their variations is of crucial importance for liver and biliary tract surgery including liver transplantation, tumor resection and laparoscopic hepatobiliary surgeries. ${ }^{2}$ Drainage of the right posterior duct into the left hepatic duct or at its confluence with the right anterior duct is the most common anatomic variant of the biliary system and is reported in about $30 \%$ of cases. ${ }^{3}$ Most of the complications in these surgeries are caused by the presence of anatomical variation of bile ducts which lead to difficult anastomosis thus increased morbidity. ${ }^{4}$ While the epidemiology of extrahepatic biliary abnormalities is well described in the literature, especially as regards pancreaticobiliary duct maljunction few data is available regarding the epidemiology of intrahepatic biliary abnormalities. ${ }^{5}$ In fact, in opposition to what has been observed for extrahepatic biliary anatomy, very few data is reported about regional or ethnical disparities, or correlation with other demographical characteristics. Different IHBD classifications have been proposed by various authors. In our study we have used the classification given by Choi et al. ${ }^{6}$ There is increasing number of case post cholecystectomy strictures, which is due to lack of prior knowledge of biliary duct anatomy. The objective of the study is to determine the percentage of population with the typical (Type 1) IHBD and atypical (Type 2 to 7 ) IHBD.

\section{METHODS}

This quantitative, cross sectional study was performed in patients referred for MRCP examinations for various clinical indications to the Department of Radiology and Imaging, Tribhuvan University Teaching Hospital, Maharajgunj, Nepal. Data were collected for a period of four months from August to November 2019 after IRB approval.

Convenience sampling was employed and a total of 90 examinations were included. Patients with history of hepatic or biliary surgery were excluded from the study. Data were obtained from the 1.5T Magnetom Amira Siemens MRI scanner. Informed consent forms were taken from the patients meeting the inclusion criteria. The routine department protocol was followed for the MRCP examinations. The patients were thoroughly screened as per department guidelines for any ferromagnetic material.. Freshly crushed pineapple juice was given to the patients prior to the examination to reduce fluid signal from the stomach. The routinely obtained sequences in TUTH are as follows:

- T2 HASTE coronal respiratory triggering: FOV $350 \mathrm{~mm}$, slice thickness $4.5 \mathrm{~mm}$, TR $2000 \mathrm{~ms}$, TE $93 \mathrm{~ms}$, slices 25 , distance factor $50 \%$, PAT 2, voxel size $1.1 \times 1.1 \times 4.5 \mathrm{~mm}$.

- T2 HASTE transverse respiratory triggering: FOV $370 \mathrm{~mm}$, slice thickness $5 \mathrm{~mm}$, TR 2000ms, TE 99ms, slices 30 , distance factor $40 \%$, PAT 2, voxel size $1.4 \times 1.4 \times 5 \mathrm{~mm}$.

- T2 FBLADE FATSAT respiratory triggering: FOV 380mm, slice thickness $6 \mathrm{~mm}$, TR $3000 \mathrm{~ms}$, TE $90 \mathrm{~ms}$, slices 30 , distance factor $30 \%$, PAT 2, voxel size $1.2 \times 1.2 \times 6 \mathrm{~mm}$.

- T2 HASTE FATSAT coronal thick slab breath hold: FOV $350 \mathrm{~mm}$, slice thickness $4.5 \mathrm{~mm}$, TR $2000 \mathrm{~ms}$, TE $93 \mathrm{~ms}$, slices 25 , distance factor $50 \%$, PAT 2, voxel size $1.1 \times 1.1 \times 4.5 \mathrm{~mm}$.

- T2 SPACE coronal respiratory triggering: FOV $380 \mathrm{~mm}$, slice thickness $1 \mathrm{~mm}$, TR $2500 \mathrm{~ms}$, TE $520 \mathrm{~ms}$, slabs 1 , slices per slab 72, no slice oversampling, PAT 2, voxel size $0.5 \times 0.5 \times 1 \mathrm{~mm}$.

The 3D SPACE images were reformatted with Maximum Intensity Projection. These images were then visually analyzed to determine the IHBD variations.

The percentage of IHBD variations according to gender were cross tabulated. The percentage of cases having normal (Type 1) and abnormal (Type 2/3A/3B/3C/4/5A/5B/6/7) were determined. Chi-square test was applied for statistical significance of IHBD variations in male and female. 


\section{RESULTS}

A total of 90 patients were selected. Among them there were 32 males and 58 females i.e. $64.4 \%$ females and $35.6 \%$ males. The mean age was found to be $46.33 \pm 17$ years. The minimum and maximum ages were 3 and 87 years respectively. (Figure 1)

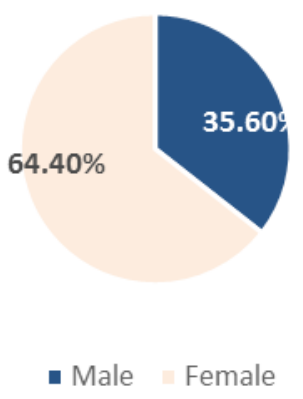

Figure 1. Pie Chart showing percentage of Males and Females.

The variations were divided into Type 1, 2, $3 \mathrm{~A}, 3 \mathrm{~B}, 4,5 \mathrm{~A}, 5 \mathrm{~B}, 6$ and 7. (Figures 3 to 9) Type 1 was considered as normal. Others were categorized as abnormal IHBD variations. Forty three patients among 90 selected for the study had Type 1 IHBD. This constituted $47.8 \%$ who had normal type of IHBD i.e. common hepatic duct is formed by fusion of the RHD and LHD. The RHD arises through fusion of the RASD, which drains anterior segments V and VIII, and the RPSD, which drains posterior segments VI and VII. (Figure 2)

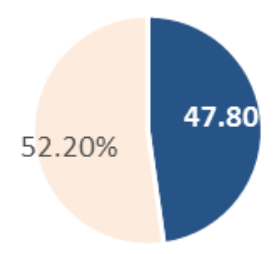

- Type 1 Others

Figure 2. Pie chart showing percentage of normal and abnormal IHBD.

Among the remaining 47 patients, 18 patients had Type 2 IHBD variation, 3 patients had Type 3A, 5 patients had Type 3B, 5 patients had Type 5A, 7 patients had Type 5B, 3 patients had Type 6 and 6 patients had Type 7 IHBD variations. No patients were found having Type $3 \mathrm{C}$ and Type 4 IHBD variations. (Table 1)

Table 1. Percentage of IHBDs.

\begin{tabular}{|l|l|l|}
\hline \multicolumn{1}{|c|}{ Type } & Frequency & \multicolumn{1}{c|}{$\begin{array}{c}\text { Percentage } \\
(\mathbf{\%})\end{array}$} \\
\hline Type 1 & 43 & 47.8 \\
\hline Type 2 & 18 & 20 \\
\hline Type 3A & 3 & 3.3 \\
\hline Type 3B & 5 & 5.6 \\
\hline Type 3C & 0 & 0 \\
\hline Type 4 & 0 & 0 \\
\hline Type 5A & 5 & 5.6 \\
\hline Type 5B & 7 & 7.8 \\
\hline Type 6 & 3 & 3.3 \\
\hline Type 7 & 6 & 6.7 \\
\hline
\end{tabular}

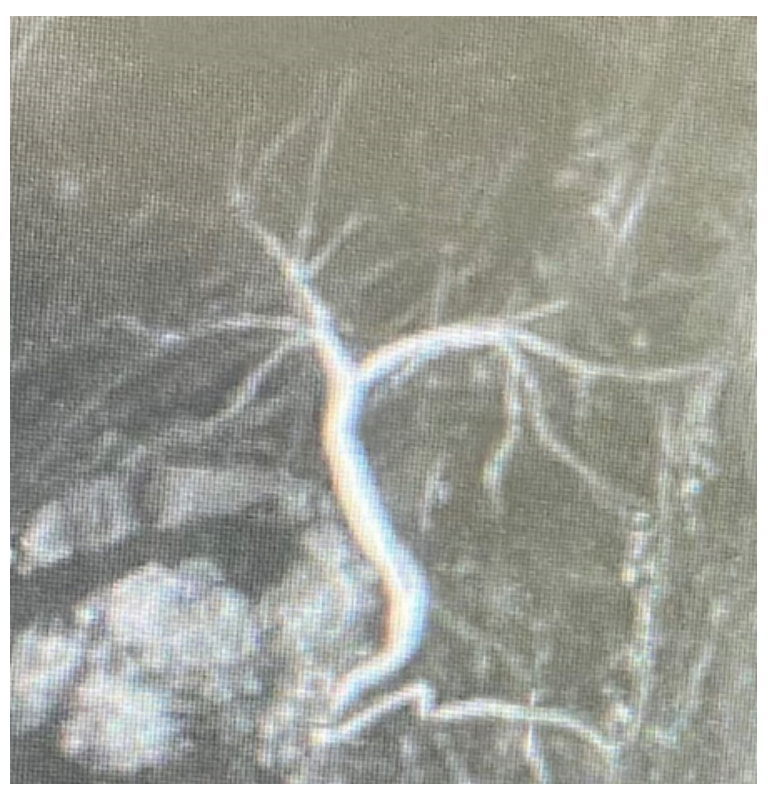

Figure 3. Type 1. The CHD is formed by fusion of the RHD and LHD. The RHD is formed by fusion of the RASD, and the RPSD. 


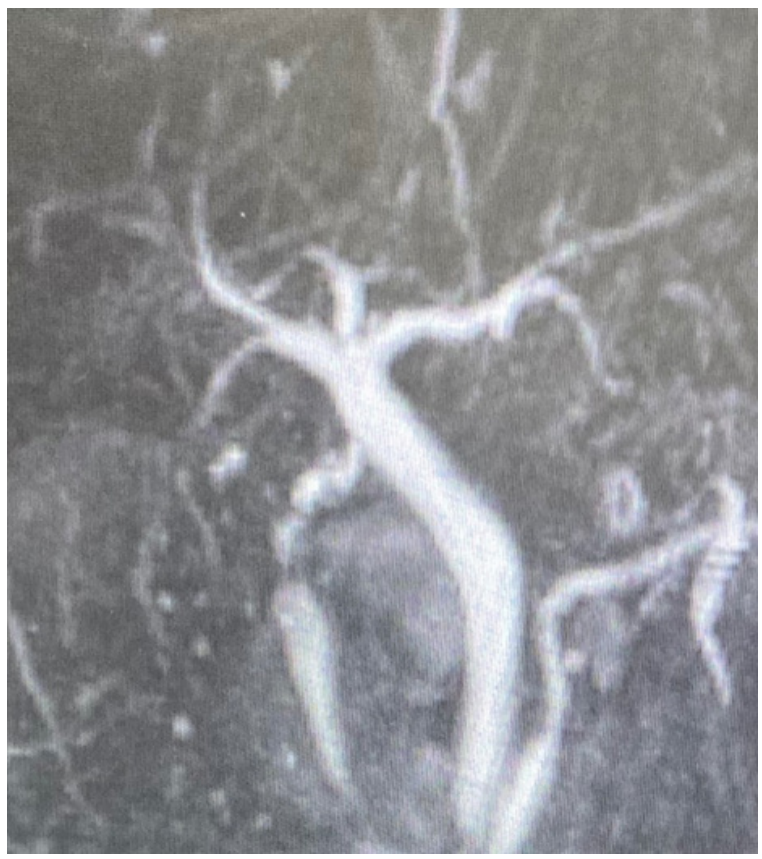

Figure 4. Type 2. It demonstrates simultaneous emptying of the RASD, RPSD and LHD into the CHD.

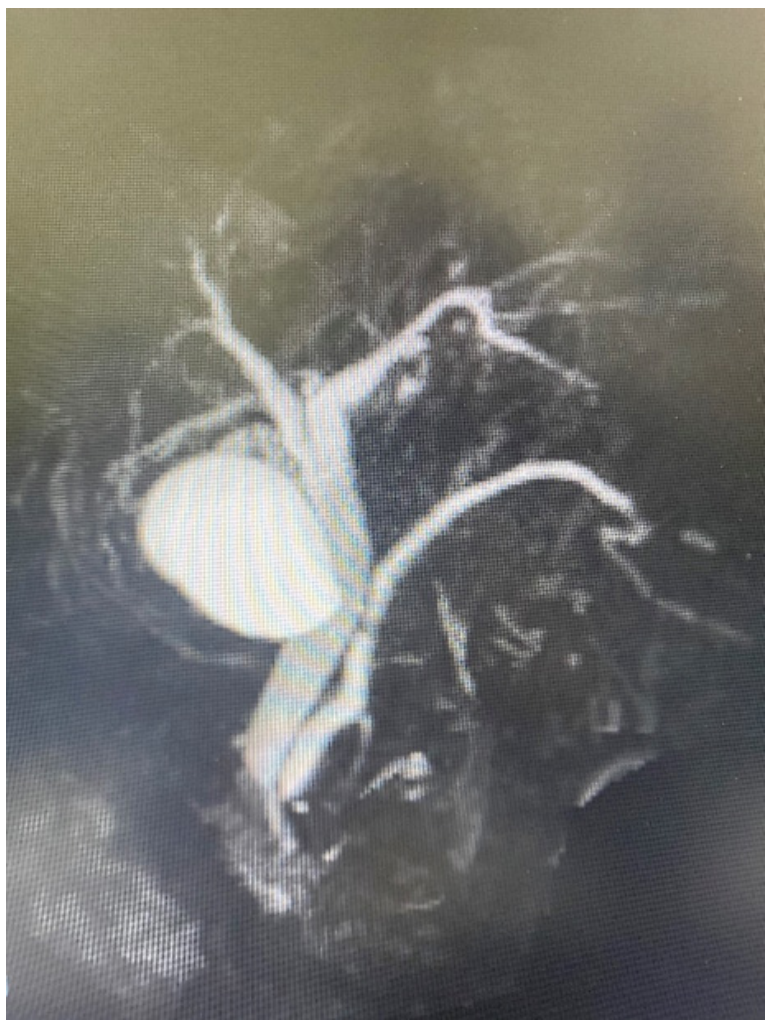

Figure 5. Type $3 A$. It demonstrates anomalous drainage of RPSD into LHD.

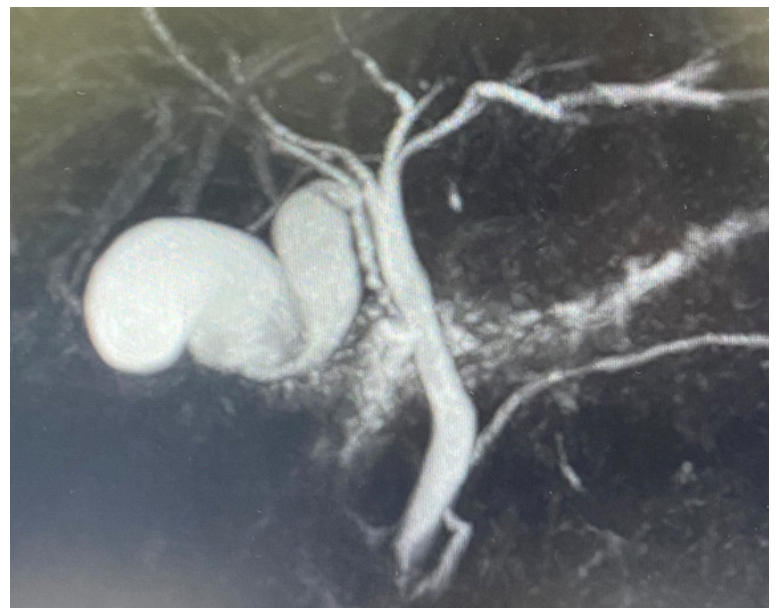

Figure 6. Type 3B. It demonstrates anomalous drainage of RPSD into the CHD.

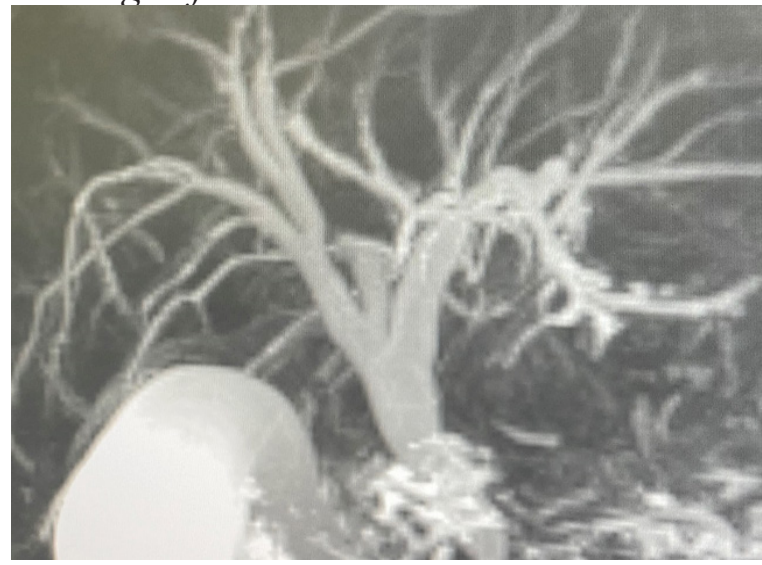

Figure 7. Type 5B. It demonstrates an accessory duct draining into the Right Hepatic Duct.

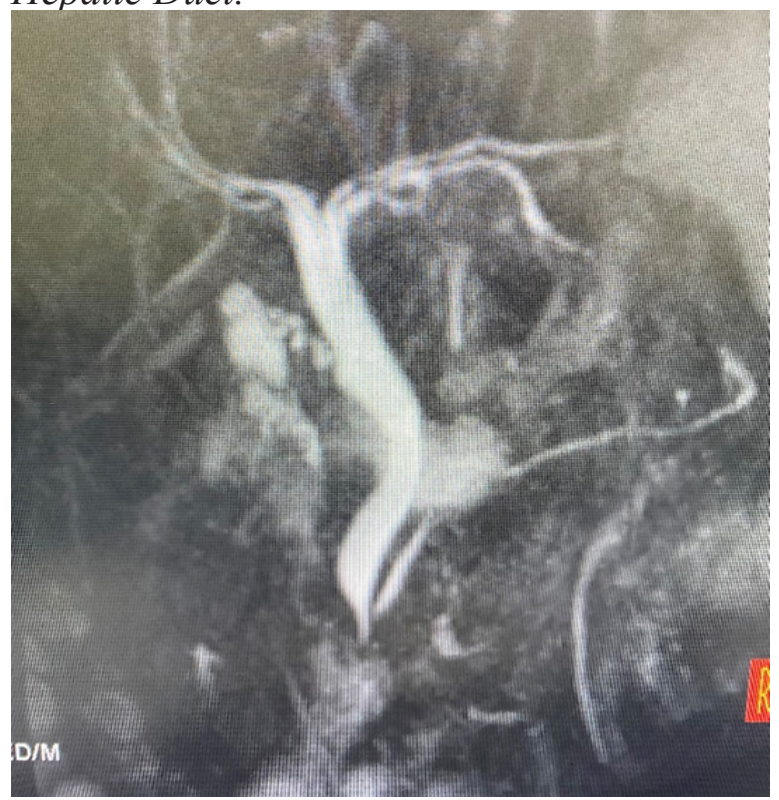

Figure 8. Type 6. It demonstrates Segments II and III of the segmental duct drain individually into the RHD or CHD. 


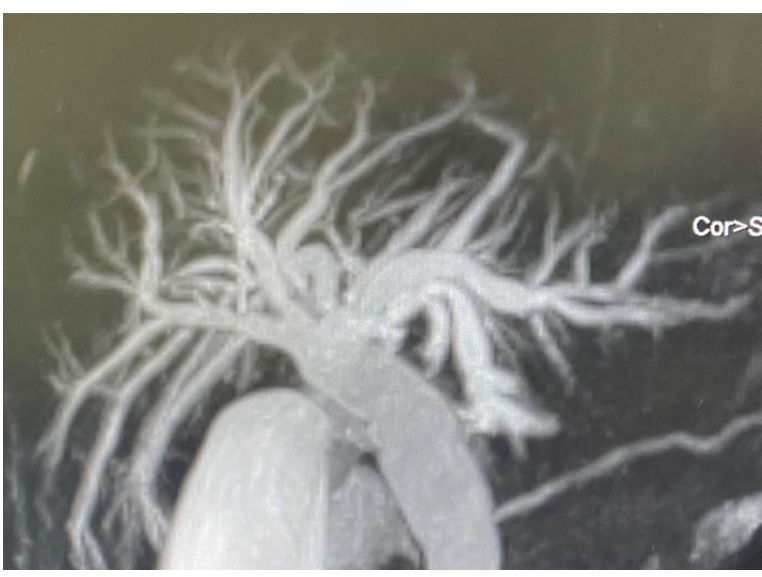

Figure 9. Type 7. Multiple accessory ducts. Sex and IHBD Types

Cross tabulation of sex and IHBD types

Among 43 patients who had Type 1, 29 were female and 14 were male.

Among 18 patients who had type 2 IHBD, 11 were female and 7 were male.

Among 3 patients who had type 3A IHBD, 2 were female and 1 was male.

Among 5 patients who had Type 3B IHBD, all were female.

Among 5 patients who had Type 5A IHBD, 3 were female and 2 were male.

Among 7 patients who had Type 5B IHBD, 3 were female and 4 were male.

Among 3 patients who had type 6 IHBD, 2 were female and 1 was male.

Among 6 patients who had Type 7 IHBD, there were 3 males and 3 female. (Table 2)

Table 2. Cross Tabulation of Sex and

\begin{tabular}{|c|c|c|c|}
\hline \multicolumn{4}{c|}{ Type. } \\
\hline & \multicolumn{2}{c}{ Sex } & \\
\hline Type & Female & Male & Total \\
\hline 1 & $29(67.4 \%)$ & $14(32.6 \%)$ & 43 \\
\hline 2 & $11(61.1 \%)$ & $7(38.9 \%)$ & 18 \\
\hline 3A & $2(66.7 \%)$ & $1(33.3 \%)$ & 3 \\
\hline 3B & $5(100 \%)$ & $0(0 \%)$ & 5 \\
\hline 5A & $3(60 \%)$ & $2(40 \%)$ & 5 \\
\hline 5B & $3(42.9 \%)$ & $4(57.1 \%)$ & 7 \\
\hline 6 & $2(66.7 \%)$ & $1(33.3 \%)$ & 3 \\
\hline 7 & $3(50 \%)$ & $3(50 \%)$ & 6 \\
\hline Total & $58(64.4 \%)$ & $32(35.6 \%)$ & 90 \\
\hline
\end{tabular}

The Chi-square statistic value obtained by the chi-square test in SPSS was 0.32 . The p-value was 0.57 i.e. the difference in IHBD variation between male and female was not significant $(\mathrm{p}>0.05)$.

\section{DISCUSSION}

Currently MRI is considered the method of choice for the study of the biliary system owing to its high sensitivity, non-invasive nature as well as absence of ionizing radiation. Due to several technical improvements introduced in its protocol over recent years, MRCP allows us to investigate the morphology of intrahepatic bile ducts and cystic duct.

The need for precise intrahepatic biliary anatomy is essential especially for the biliary interventional procedures as well as liver surgery like liver resection and transplantation and to reduce biliary complications. 7,8 While biliary anatomical variants are not a contraindication for liver donation, however, detailed accurate pre-operative identification is essential to avoid severe post-surgical morbidity and complications.

There is a high prevalence of biliary variants which was shown in many previous studies. ${ }^{6}$ Normal or Type 1 IHBD was found in only 43 patients consisting of $47.8 \%$ among the 90 patients included in the study. In the current study, we used the classification given by Choi et al. ${ }^{6}$ In their study anatomical variation in IHBDs was classified according to the branching pattern of the right anterior and right posterior segmental duct (RASD and RPSD, respectively) and the presence or absence of the first-order branch of the left hepatic duct (LHD) and of an accessory hepatic duct. They found the normal/Type 1 IHBD in $63 \%$ subjects $(n=188)$. Our study found a lower percentage of normal IHBD i.e. $47.8 \%$ subjects. This difference may be in part due to the smaller sample size used in our study (90 v/s 300 in previous study). The study by Choi et al. ${ }^{6}$ was obtained from carefully selected liver donors who underwent an intraoperative cholangiogram. Thus our study may be more representative of the general population. Similarly, normal or Type 1 IHBD was found in $55 \%$ cases by 
Cocuzza $G$ et al. ${ }^{7}$ They studied the MRCP examinations of 534 patients. Nayman et al. ${ }^{9}$ found normal IHBD in $62 \%$ cases. They studied MRCP examinations of 2624 patients and also provided classification for 10 novel variations encountered by them.

In our study, the triple confluence/ Type 2 IHBD was encountered in $20 \%$ subjects $(\mathrm{n}=18)$. Previous studies by Choi and Coccuza $\mathrm{G}$ both found similar type of biliary anatomy in $10 \%$ cases. ${ }^{6,7}$ Type 2 IHBD was encountered in $9 \%$ of the cases in a study by Nayman et al. ${ }^{9}$ Type 3 representing anomalous drainage of the right posterior sectoral duct was subdivided into $3 \mathrm{~A}, 3 \mathrm{~B}$ and $3 \mathrm{C}$ by Choi et al. ${ }^{6}$ In our study $3 \mathrm{~A}$ i.e. RPSD drains into LHD in $3.3 \%$ subjects $(n=3)$. In the study by Choi et al. ${ }^{6}, 3 \mathrm{~A}$ constituted $11 \%$ of the total cases. Cocuzza et al. ${ }^{7}$ found it to be the second most frequent IHBD variation with $19.8 \%$. Type 3B i.e. RPSD draining into the common hepatic duct was found in $5.6 \%$ cases $(n=5)$. The study by Choi found Type 3B IHBD in 6\% cases. ${ }^{6}$ Cocuzza found this type of variation in $6.74 \%$ cases. $^{7}$ Type $3 \mathrm{C}$ i.e. RPSD draining into the cystic duct was not encountered in our study. However Choi found such type of variation in $2 \%$ cases. ${ }^{6}$ Nayman et al. ${ }^{9}$ found Type 3 IHBD in 11\% cases. We found Type 3 IHBD in $8.9 \%$ cases.

No cases having Type 4 IHBD was observed in our study. The study by Choi found only 1 Type 4 IHBD case. $^{6}$

Type 5 in which an accessory duct is present was further sub divided into $5 \mathrm{~A}$ and $5 \mathrm{~B}$. In $5 \mathrm{~A}$, the accessory duct drains into the common hepatic duct. This was found in $5.6 \%$ cases $(n=5)$ in our study. While Choi found this type in $3 \%$ cases. ${ }^{6}$ In $5 \mathrm{~B}$, accessory duct drains into the Right Hepatic Duct. This type of variation was found in $7.8 \%$ cases $(n=7)$. The study by Choi et al. ${ }^{6}$ reported this type in $3 \%$ cases.

Type 6 is one in which segments II and III of the segmental duct drain individually into the RHD or CHD. This type of variation was only found in $1 \%$ cases in Choi's study. ${ }^{6}$ However we found 3 cases with Type 6 IHBD that constituted $3.3 \%$.

Type 7 includes the variations that don't fall into any of the above Types and hence includes the unclassified/ complex variations. The study by Choi found 3 cases belonging to Type 7, whereas we found 6 cases constituting $6.7 \%$ of the total cases. ${ }^{6}$ Among the 6 patients, in 2 patients the cystic duct drained into right hepatic duct, in 4 patients there were numerous accessory ducts draining into CHD and RHD. No significant difference was found in the IHBD variations in between male and female $(p>0.05)$ as given by Chi-square test.

\section{CONCLUSIONS:}

MRCP is the modality of choice for evaluation of hepatobiliary anatomy. Typical IHBD was only found in $47.8 \%$ patients and common other variations were also noted in our population. Type 2 was found in $20 \%$ and Type 5B was found in $7.8 \%$ patients. Type $3 \mathrm{C}$ and Type 4 variations were not found in our study. Detailed, accurate pre-operative identification of biliary anatomical variants is essential to avoid severe post-surgical morbidity and complications.

\section{CONFLICT OF INTEREST}

None

\section{SOURCES OF FUNDING}

None

\section{REFERENCES}

1. Gupta RT, Brady CM, Lotz J, Boll DT, Merkle EM. Dynamic MR imaging of the biliary system using hepatocyte specific contrast agents. AJR Am J Roentgenol 2010;195(2):405-13. https:// doi.org/10.2214/AJR.09.3641

2. Sin YL, Kuang TP, Sung YC et al. Common and rare variants of the biliary tree: magnetic resonance cholangiographic findings and clinical implications. JRadiol Sci 2012;37(2):59-67. http://dx.doi.org/1 0.6698\%2fJRS.201206 3702.02

3. Puente SG, Bannura GC. Radiological 
anatomy of the biliary tract: variations and congenital abnormalities. World $J$ Surg 1983; 7(2):271-6. https://doi. org/10.1007/BF01656159

4. Karakas HM, Celik T, Alicioglu B. Bile duct anatomy of the Anatolian Caucasian population: Huang classification revisited. Surg Radiol Anat 2008;30(7):539-45. https://doi.org/10.1007/s00276-0080365-y

5. Kamisawa T, Takuma $\mathrm{K}$, Anjiki $\mathrm{H}$ et al. Pancreatico biliary maljunction. Clin Gastroenterol Hepatol 2009;7(11):S84-8. https://doi.org/10.1016/j.cgh.2009.08.024

6. Choi JW, Kim TK, Kim KW et al. Anatomic Variation in Intrahepatic Bile Ducts: an Analysis of Intraoperative Cholangiograms in 300 Consecutive Donors for Living Donor Liver Transplantation. Korean $J$ Radiol 2003;492):85-90. https://doi.org/10.3348/ kjr.2003.4.2.85

7. Piana S, Piccoli $\mathrm{M}$, Roccasalva $\mathrm{F}$ et al. Anatomic variants of the biliary tree: a retrospective Magnetic Resonance Cholangiopancreatography (MRCP) evaluation. European Congress of Radiology 2017. https://dx.doi. org/10.1594/ecr2017/C-2417

8. Mortelé KJ, Ros PR. Anatomic variants of the biliary tree: MR cholangiographic findings and clinical applications. AJR Am J Roentgenol 2001;177(2):389-94. https:// doi.org/10.2214/ajr.177.2.1770389

9. Nayman A, Özbek O, Erol S, Karakuş $\mathrm{H}$, Kaya HE. Magnetic resonance cholangiopancreatography evaluation of intrahepatic bile duct variations with updated classification. Diagn Interv Radiol 2016;22(6):489-94. https://doi. org/10.5152/dir.2016.16051 